\title{
High temperature behaviour and oxidation resistance of carbon-boron- nitrogen compounds obtained by LPCVD
}

\author{
A. DERRE, L. FILIPOZZI and F. PERON \\ CNRS, Centre de Recherche Paul Pascal, avenue A. Schweitzer, 33600 Pessac, France
}

\begin{abstract}
Coatings of carbon-boron-nitrogen compounds with various compositions are obtained in a low pressure chemical vapour deposition process using acetylene, boron trichloride, ammonia and hydrogen as input gases. Compositions are located in the ternary system C-BN-"BC 3 ". The structure of the films is a graphitic turbostratic one for the whole composition range but carbonrich deposits exhibit greater coherence length $\mathrm{L}_{\mathrm{c}}$ than boron nitride-rich ones.

The high temperature behaviour is studied for three specific compositions: $\mathrm{C}_{0.82} \mathrm{~B}_{0.14} \mathrm{~N}_{0.04}, \mathrm{C}_{0.50} \mathrm{~B}_{0.31} \mathrm{~N}_{0.19}$ and $\mathrm{C}_{0.78} \mathrm{~B}_{0.22}$.

In an inert atmosphere no mass loss is observed up to $2250^{\circ} \mathrm{C}$ while graphitization and formation of boron carbide occur. Based on electron probe micro analysis, depletion of boron and nitrogen happens only in the few micrometers near the surface of the sample. Above $2500^{\circ} \mathrm{C}$, $\mathrm{B}_{13} \mathrm{C}_{2}$ evaporates and a graphite-like material is formed.

In a dry air atmosphere, oxidation occurs above $800^{\circ} \mathrm{C}$ with a slow kinetics. A boron oxide layer protects the sample up to $1000^{\circ} \mathrm{C}$. Above this temperature, volatilization of $\mathrm{B}_{2} \mathrm{O}_{3}$ occurs and oxidation is greatly enhanced. Of special interest seems to be the $\mathrm{C}_{0.78} \mathrm{~B}_{0.22}$ coating which exhibits the lowest oxidation rate. Such deposits could then present a way to protect carboncarbon composites at moderate temperature in the form of an external coating or better of an intermediate layer between fibres and matrix.
\end{abstract}

\section{INTRODUCTION}

Since Badzian et al. [1] reported the co-deposition of carbon, boron and nitrogen in 1972, a few authors have tried to make such compounds, see for example [2-8].

The very similar crystalline structures of graphite and boron nitride (hexagonal type) strongly suggest the synthesis of alloys or solid solutions of $\mathrm{a} \mathrm{C}_{\mathrm{x}}(\mathrm{BN})_{1-\mathrm{x}}$ type, despite the ternary phase diagram only shows the binary compounds boron nitride $B N$ and boron carbides such $B_{50} C_{2}, B_{8} C$ (both are low temperature compounds) or $\mathrm{B}_{13} \mathrm{C}_{2}$ (figure 1 [9]). According to Lowell [10], boron substitution in graphite does not exceed 2.35 at $\%$ at $2623 \mathrm{~K}$ (figure 2 [10]), and such a phase (C-B-N compound) could only be a metastable one.

From the very different electronic properties of graphite which is a semi-metal and hexagonal boron nitride which is an insulator could emerge a novel class of materials with interesting adjustable conducting properties since such heavy doping of a graphitic carbon with unequal amounts (see further on) of acceptor (boron) and donor (nitrogen) should result in drastic alterations of the electronic energy levels.

Graphite is also well known for the numerous chemical species which can be intercalated between the (002) planes of the hexagonal structure. In the other hand there are few boron nitride intercalation products, so the carbon-boron-nitrogen compounds offer a great interest for material science research. 
Another aspect is the improvement of the carbon oxidation resistance that could induce boron substitution. Composite materials using carbon as fibres and / or matrix, despite their very high mechanical properties, offer a poor oxidation behaviour that limits their application. The addition of oxidation inhibitors into the matrix has already been investigated in order to increase the life time of such carbon materials, and boron in particular seems to be a good candidate for this purpose [11,12]. The problem is to increase the boron content over the 2 at\% content generally used to further improve the oxidation resistance.

In order to explore these new possibilities, we have carried on a study of the high temperature behaviour and oxidation resistance of some selected compositions of carbon-boron-nitrogen compounds.

\section{MATERIALS AND EXPERIMENTAL SET UP}

L.P.C.V.D. is very often used and boron trichloride $\mathrm{BCl}_{3}$ and ammonia $\mathrm{NH}_{3}$ are commonly selected as boron and nitrogen precursors. But a lot of carbonaceous species as acetylene $\mathrm{C}_{2} \mathrm{H}_{2}[3,6,8]$, benzene $\mathrm{C}_{6} \mathrm{H}_{6}[2,4]$, methane $\mathrm{CH}_{4}[5,6,7]$, propane $\mathrm{C}_{3} \mathrm{H}_{8}[5,6]$ or acetonitrile $\mathrm{CH}_{3} \mathrm{CN}$ [4] could be chosen as carbon precursor.

We previously reported [13] the preparation of films of carbon, boron and nitrogen from mixtures of acetylene, boron trichloride, ammonia and hydrogen. These films can be deposited on various substrates (graphite , alumina, pyrolytic boron nitride, silica) at temperatures ranging from 1000 to $1250^{\circ} \mathrm{C}$, under pressures of 10-60 millibars. Their surface is extremely smooth and mirror-like.

Figure 3 shows in a C-B-N triangular diagram the range of compositions which can be obtained: the carbon content can vary from 0 to $100 \%$ while the $B / N$ ratio is always larger than unity. The $C_{x}(B N)_{1-x}$ formula is then not convenient to describe these materials. Otherwise they cannot be presented as a simple substitution of boron nitride for carbon. An interesting particular composition is $\mathrm{BC}_{3}$ that seems to be the limit above which the films are not single-phase ones, boron carbide $\mathrm{B}_{13} \mathrm{C}_{2}$ being present as a codeposited material. In the C-BN-"BC 3 " white triangle, X-Ray Diffraction (XRD) shows only the lines of a turbostratic, graphite-like crystal lattice, as could be expected from the extremely similar structures of hexagonal boron nitride and graphite.

Three homogeneous series of samples were prepared for the oxidation studies that are reported in figure 3 as $A, B$ and $C$ compositions. Slightly different samples (so called $A^{\prime}, B^{\prime}$ and $C^{\prime}$ ) were also used for the high temperature treatments.

Compositions were determined using Electron Probe Micro Analysis (EPMA). Sample A, B and C agree with the $C_{0.50} B_{0.31} N_{0.19}, C_{0.78} B_{0.22}$ and $C_{0.82} B_{0.14} N_{0.04}$. formulae respectively. The $A^{\prime}, B^{\prime}$ and $\mathrm{C}^{\prime}$ compositions are reported in table 1 . The reliability of EPMA on these materials was preliminary checked by means of Rutherford Back Scattering measurements. We think so that dubiousness of boron and nitrogen amounts is about \pm 2 at\%.

High temperature treatments were performed in a graphite resistor furnace under an argon flow and a pressure of $1 \mathrm{~atm}$. Samples were prepared on alumina plates. The expansion coefficient mismatch between deposit and substrate $\left(\alpha=8.4 \times 10^{-6} \mathrm{~K}^{-1}\right.$ for $\mathrm{Al}_{2} \mathrm{O}_{3}$ and $\alpha=1$ to $2 \times 10^{-6} \mathrm{~K}^{-1}$ for carbon) leads the layer to flake off during the temperature fall at the end of the experiment. The only film was then put in a graphite crucible and heat-treated during one hour. Heat-treatments were performed at 1500, 1750, 2000, 2250 and $2500^{\circ} \mathrm{C}$ (HTT for highest treatment temperature) and resulting materials were analysed by EPMA. The weight loss and the layer stacking evolution were both measured. We used a Siemens diffractometer with a $\mathrm{Cu}$ x-ray tube in a flat plate sample geometry and an Inel CPS 120 curved detector. The angle between the sample and the incoming beam was set at a $13^{\circ}$ value in order to increase the sensitivity of the $d_{002}$ spacing measurement. The samples were put as flakes on a silica support but no large amount of diffuse scattering from this support was seen because of the incidence angle and the thickness of the samples $(t>20 \mu \mathrm{m})$.

Oxidation resistance was investigated in the high temperature vertical alumina hot wall reactor shown in figure 4. The precision of the balance is $0.1 \mathrm{mg}$. Temperature was fixed at $800,900,1000$ and $1100^{\circ} \mathrm{C}$ and was measured by a thermocouple. The rate of heating was $300^{\circ} \mathrm{C} \mathrm{h}^{-1}$. The samples were coated silica substrates and directly hanged with platinum wire. Therefore mass variation is only due to the carbonboron-nitrogen materials alteration. Their dimensions were $(25 \times 5 \times 1.5) \mathrm{mm}^{3}$. The thickness of the 
deposits is $24 \mu \mathrm{m}$ for sample A, $93 \mu \mathrm{m}$ for sample B and $80 \mu \mathrm{m}$ for sample C. These coatings were subjected to an oxidizing atmosphere of dry air flowing at 15 standard-1 $\mathrm{h}^{-1}$ (inner diameter of the alumina tube $\emptyset=25 \mathrm{~mm}$ ). Total pressure was set at 1040 millibars by means of a needle valve.

\section{RESULTS AND DISCUSSION}

Table 1 summarizes the composition variations for samples $A^{\prime}, B^{\prime}$ and $C^{\prime}$ as a function of heat treatment temperature. It can be immediately pointed out that drastic alterations seem to occur and that in the three cases, the composition after one hour at $2500^{\circ} \mathrm{C}$ is very close to that predicted by the phase diagram (keeping in mind the dubiousness of chemical analysis): boron can substitute for carbon only to a low extent $\left(2.0\right.$ at $\%$ at $2500^{\circ} \mathrm{C}$, see figure 2$)$. According to XRD, a single graphite-like material is present at this temperature. Nevertheless another phase appears from 1750 to $2250^{\circ} \mathrm{C}$. Additional lines are seen on XRD spectra wich can be assigned to the $\mathrm{B}_{13} \mathrm{C}_{2}$ boron carbide. The relative intensity of these lines is very low compared to that of the graphite structure and exhibits a maximum at $2000^{\circ} \mathrm{C}$. This suggests that boron carbide formation starts from $1750^{\circ} \mathrm{C}$ by solid state diffusion of boron, then, over $2400^{\circ} \mathrm{C}$, the eutectic temperature, the phase diagram indicates that a liquid can form. This could promote the growth of boronrich micro domains. But in the same time sublimation or decomposition of this liquid could be enhanced so that after one hour at $2500^{\circ} \mathrm{C}$ the whole boron-rich liquid disappears. Quantitative analysis of the $\mathrm{B}_{13} \mathrm{C}_{2}$ amount is not realistic due to the very strong preferential orientation of the crystallites forming the film, with their $c$ axis upright to the substrate. XRD patterns only show the (002) and the (004) lines.

Table 2 indicates the mass loss $\left(\Delta \mathrm{m}_{\text {exp }}\right)$ of the three samples. Heat treatments for both $A^{\prime}$ and $C^{\prime \prime}$ samples do not result in any noticeable loss of mass up to $2250^{\circ} \mathrm{C}$. The only $\mathrm{B}^{\prime}$ sample starts to "evaporate" at $2250^{\circ} \mathrm{C}$. These results are in complete disagreement with the former chemical analysis. The $\Delta \mathrm{m}_{\text {calc }}$ column of table 2 helps to compare to the theoric mass loss based on EPMA results, assuming there is no carbon departure. It can be seen that the mass loss should be more progressive and start slowly from $1500^{\circ} \mathrm{C}$ up to $2500^{\circ} \mathrm{C}$. To explain this unexpected mismatch we could suggest two reasons. First, the decrease in both boron and nitrogen concentrations is actually due to an "accidental" increase in the surface carbon content. Additional carbon from the furnace walls and / or the crucible could deposit on the sample surface. This is not consistent with complementary experiments which show that longer treatment duration (three hours) affects neither the composition nor the absolute mass loss. The second possibility is that the analysed thickness has not an uniform composition: an effective decrease in both boron and nitrogen contents occurs, but located in the very few micrometers under the external surface of the sample (for the EPMA conditions used, the analysed thickness is thinner than $1.4 \mu \mathrm{m}$ ). Such changes in surface composition were previously pointed out for titanium carbide $\mathrm{TiC}$, boron carbide $\mathrm{B}_{4} \mathrm{C}$ or silicon carbide $\mathrm{SiC}$ [14]. Using Auger Electron Spectroscopy (AES), these authors reported that during heat treatment, an increase in the surface composition of the carbon atoms was observed, leading to graphite-type carbon atoms in the near-surface region. In the present case, a bulk alteration of the material with a simultaneous loss of mass happens only above $2250^{\circ} \mathrm{C}$. Experimental values of $\Delta \mathrm{m}_{\exp }$ also suggest that at $2500^{\circ} \mathrm{C}$ sample $\mathrm{B}^{\prime}$ could correspond to the saturated solid solution of boron in graphite corresponding approximatively to the $\mathrm{C}_{0.98} \mathrm{~B}_{0.02}$ formula (see figure 2). The $\mathrm{C}_{0.79} \mathrm{~B}_{0.21} \cdots \cdots \mathrm{C}_{0.98} \mathrm{~B}_{0.02}$ "transformation" should result in a $-17.7 \%$ relative mass loss, very close to the $-17.2 \%$ experimental value. Concerning the samples $\mathrm{C}^{\prime}$ and $\mathrm{A}^{\prime}$ the same calculations lead to $-22.4 \%$ (experimental value = $18.9 \%$ ) and $-43.7 \%$ (experimental value $=-24.7 \%$ ) respectively. These increasing "gaps" suggest that nitrogen contributes to stabilize the mean bulk composition of the materials. A likely explanation could be that solid state diffusion of boron and / or nitrogen leads to the formation of boron nitride-rich micro domains or micro phases "encapsulated" into the carbon matrix. A rough attempt to fit the experimental mass loss and support this (assuming there is no carbon loss) leads to the global evaluations:

$$
\begin{aligned}
& \text { sample } C^{\prime} \\
& \begin{array}{c}
\mathrm{C}_{0.76} \mathrm{~B}_{0.15} \mathrm{~N}_{0.09}-->0.775 \mathrm{C}_{0.98} \mathrm{~B}_{0.02}+ \\
\Delta \mathrm{m}_{\text {th }}=-18.9 \%=\Delta \mathrm{m}_{\exp }
\end{array} \\
& +0.024 \mathrm{BN} \\
& \mathrm{C}^{\prime} \mathrm{BN}=0.024 \\
& \mathrm{C}_{0.55} \mathrm{~B}_{0.29} \mathrm{~N}_{0.16} \cdots 0.563 \mathrm{C}_{0.98} \mathrm{~B}_{0.02}+0.096 \mathrm{BN} \\
& \Delta \mathrm{m}_{\mathrm{th}}=-24.7 \%=\Delta \mathrm{m}_{\mathrm{exp}} \\
& \mathrm{A}_{\mathrm{BN}}^{\prime}=0.096
\end{aligned}
$$


The final materials $\mathrm{C}^{\prime}$ and $\mathrm{A}^{\prime}$ could be nano composites corresponding to a $3 \mathrm{~mol} \%$ and a $17 \mathrm{~mol} \%$ dispersion of $\mathrm{BN}$ into boron saturated carbon $\mathrm{C}_{0.98} \mathrm{~B}_{0.02}$ respectively.

It can also be noticed that more boron nitride should form if no nitrogen (and no carbon) escaped from the materials:

$$
\begin{aligned}
& \text { sample } \mathrm{C}^{\prime}
\end{aligned}
$$

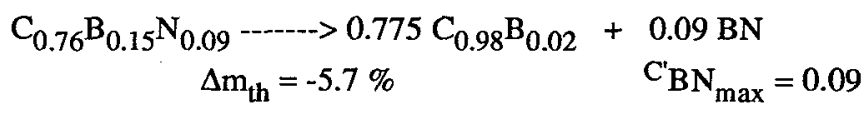

$$
\begin{aligned}
& \text { sample } A^{\prime}
\end{aligned}
$$

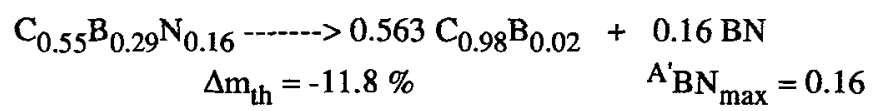

The ratios $\mathrm{X}_{\mathrm{BN}}^{\prime} / \mathrm{X}_{\mathrm{BN}}^{\prime}{ }_{\max }$ for samples $\mathrm{C}^{\prime}$ and $\mathrm{A}^{\prime}$ are 0.27 and 0.60 respectively. That can be read as a good sign of the solid solution "aspect" of the "as deposited" material. If a multi phased material was deposited (most probably $\mathrm{C}_{0.98} \mathrm{~B}_{0.02}+\mathrm{BN}+$ amorphous $\mathrm{B}_{13} \mathrm{C}_{2}$ according to the phase diagram), this ratios should be equal to unity, the already synthesized boron nitride remaining stable during the high temperature treatment. The difference between ${ }^{\prime}{ }_{B N} / C_{B N}^{\prime}$ and ${ }^{A^{\prime}}{ }_{B N} / A_{B N}^{\prime} N_{\max }$ could then indicate that the probability of boron nitride precipitates is function of the "dilution" of both boron and nitrogen into the carbon surroundings.

Figure 5 shows the variation of the spacing between the $(002)$ planes $\left(\mathrm{d}_{002}\right)$ and figure 6 shows the full width at half maximum (FWHM) of this (002) peak as a function of HTT. This behaviour is typical of the graphitization of carbons. Low temperature deposited pyrolytic carbon always presents an important crystalline disorder and is called turbostratic. It means that random rotations (and translations) are present between the adjacent layers of graphene. This leads to fluctuations in the $\mathrm{d}_{002}$ spacing and then to a broadening of the diffraction pattern for $(00 \mathrm{~h})$ peaks. This lack of three-dimension order exhibits also very poor diffraction for the $(h k l) h \neq 0$ and / or $k \neq 0$. High temperature treatments allow some rearrangements of the planes which lead the (002) peak to sharpen and the $\mathrm{d}_{002}$ to tend to the pure crystalline graphite value of $3.354 \AA[10]$ for a $\mathrm{HTT}$ of $3000^{\circ} \mathrm{C}$. $\mathrm{C}_{\mathrm{x}} \mathrm{B}_{\mathrm{y}} \mathrm{N}_{1-\mathrm{x}-\mathrm{y}}$ behaviour is qualitatively very similar, but some differences with pyrolytic carbon can be noticed. First is a smaller disorder for the "as deposited" materials. Carbons deposited between 1000 and $1200^{\circ} \mathrm{C}$ even show a d $\mathrm{d}_{002}$ distance greater than $3.45 \AA$. This effect of boron on crystallinity and easier graphitization of carbon has already been observed $[15,16]$. More surprising is the significant "inflating" of the carbon-rich materials when treated at $1500^{\circ} \mathrm{C}$. Up to now, no satisfactory interpretation of this phenomenon has been proposed. We can only suggest that prior to the formation of boron carbide $B_{13} C_{2}$, deformation of the hexagonal planes of graphene could localy occur due to a chemical bonding (between carbon and boron) effect or to a displacement of some boron atoms on intersticial sites.

The final states at $2500^{\circ} \mathrm{C}$ for the three samples are similar. FWHM is approximatively equal to $0.18^{\circ}$ which is the lower limit imposed by the XRD experimental apparatus. The $d_{002}$ value of sample $B^{\prime}$ is $3.350 \AA$. Lowell [10] shows that addition of boron in graphite leads to a slight decrease of the $d_{002}$ value. For boron satured graphite $\mathrm{C}_{0.98} \mathrm{~B}_{0.02}$ he measured a (002) plane spacing of $3.349 \AA$. This is consistent with our assumption about the sample $B^{\prime}$ behaviour. Samples $A^{\prime}$ and $C^{\prime}$ show smaller $\mathrm{d}_{002}$ values: 3.339 and $3.327 \AA$ respectively, which are more consistent with the value of pure crystalline boron nitride $\left(\mathrm{d}_{001}\right.$ $=3.335 \AA$ [17]). This trend was foreseeable if we consider as aforesaid that these samples are boron nitride dispersion in graphite. Nevertheless, this decrease seems to be too important considering the low calculated grades of boron nitride ( 3 and $17 \mathrm{~mol} \%$ respectively for $C^{\prime}$ and $A^{\prime}$ samples), and no double peak is seen on XRD patterns. We may suggest that these composites are nanometric scale ones and that high mechanical strains may occur due to both mechanical and expansion mismatches between boron saturated graphite $\left(\mathrm{C}_{0.98} \mathrm{~B}_{0.02}\right)$ and boron nitride. Internal strains are known to act about crystal planes spacing and such effect could be enhanced in very unisotropic materials (intrinsic and orientation texture unisotropy), but it is currently hazardous to be more categorical.

Figures $7,8,9$ respectively show the mass loss relative to initial mass as a function of time for samples A, B, C in dry air atmosphere and at temperatures of 800,1000 and $1200^{\circ} \mathrm{C}$. Care must be taken of the 
coating thicknesses which are strongly different: $24 \mu \mathrm{m}$ (sample A), $93 \mu \mathrm{m}$ (sample B) and $80 \mu \mathrm{m}$ (sample C). Interpretation of such curves is not easy. Precise chemical composition is difficult to obtain with EPMA due to the isolating character of the oxidized films, but these analyses only show boron and oxygen. We could then assume that oxidation of materials occurs leading most probably to the formation of boron oxide $\mathrm{B}_{2} \mathrm{O}_{3}$, which simultaneously sublimates. For the three samples, mass loss begins at almost $800^{\circ} \mathrm{C}$. Let us consider the global reaction:

$$
\mathrm{C}_{\mathrm{x}} \mathrm{B}_{\mathrm{y}} \mathrm{N}_{1-\mathrm{x}-\mathrm{y}}+(3 \mathrm{y} / 2+2 \mathrm{x}) \mathrm{O}_{2} \cdots \mathrm{y} / 2 \mathrm{~B}_{2} \mathrm{O}_{3}+\mathrm{xCO}_{2}+(1-\mathrm{x}-\mathrm{y}) / 2 \mathrm{~N}_{2}
$$

If boron oxide remains a condensed phase, complete oxidation of initial material leads to a relative mass loss of $-10.2 \%$ (sample A), $-34.8 \%$ (sample B) and $-59.1 \%$ (sample C). This latter shows, at 1200 , 1000 and $900^{\circ} \mathrm{C}$, a step or a breaking of the slope which corresponds approximatively to the calculated value. We then suggest that the whole $80 \mu \mathrm{m}$ thick coating oxidize rapidly (between 6 and $8 \mathrm{~h}$ above $1000^{\circ} \mathrm{C}$ ). After that the boron oxide volatilizes at a temperature depending rate. At $800^{\circ} \mathrm{C}$, oxidation is not complete after $20 \mathrm{~h}$, but no passivation film is formed. These phenomena are not so clear for sample A, but no protective film forms in this case too. Nevertheless this material composition should be worth investigated with a greater initial thickness. More interesting is sample B behaviour. At $1200^{\circ} \mathrm{C}$, oxidation is complete after $16 \mathrm{~h}$ without any steep change of the mass loss rate, indicating that a single mechanism should limit this rate. With decreasing temperature the behaviour is better and better and it seems that after a first step of "passivation" no oxidation occurs at $800-1000^{\circ} \mathrm{C}$. Do not forget that this material is mainly carbon (78 at\%) and this result is to be compared for example with a carbon - carbon composite (CCC) submitted to the same treatment. Figure 10 shows the mass loss of a bulk CCC (initial mass $=367 \mathrm{mg}$ ) of same geometry as the previous coated silica substrates.

\section{CONCLUSIONS}

We have presented results about the characterization in inert and oxidizing atmospheres of some selected carbon-boron and carbon-boron-nitrogen compounds obtained by LPCVD.

Under inert atmosphere, boron carbide $\mathrm{B}_{13} \mathrm{C}_{2}$ appears in very few amounts from $1750^{\circ} \mathrm{C}$ up to $2250^{\circ} \mathrm{C}$ and decomposes above this temperature. No bulk mass loss occurs up to $2250^{\circ} \mathrm{C}$ but only some boron and nitrogen depletion for the very few micrometers below the outer surface. The real nature of the heat treated materials may be a nanometric scale dispersion of boron nitride $\mathrm{BN}$ and boron saturated graphite $\mathrm{C}_{0.98} \mathrm{~B}_{0.02}$ The quality of the crystalline organisation increases with the carbon content of the coatings and the order of the layers stacking, as characterized by the (002) XRD line, can be considerably improved.

Carbon-boron $\mathrm{C}_{0.78} \mathrm{~B}_{0.22}$ compound exhibits interesting oxidation resistance between 800 and $1000^{\circ} \mathrm{C}$ which could be a way to protect the carbon fibres of composite materials at moderate temperature.

[1] BADZIAN A. R., NIEMYSKI T., APPENHEIMER S., OLKUSNIK E.,Proceedings of the 3rd International Conference on Chemical Vapor Deposition, edited by F. A. Glaski, American Nuclear Society, Hinsdale IL, 747-753, (1972)

[2] KOUVETAKIS J., KANER R. B., SATTLER M. L., BARTLETT N., J. Chem. Soc., Chem. Commun., 1758-1759, (1986)

[3] KANER R. B., KOUVETAKIS J., WARBLE C. E., SATTLER M. L., BARTLETT N., Mat. Res. Bull., Vol. 22, 399-404, (1987)

[4] KOUVETAKIS J., SASAKI T., SHEN C., HAGIWARA R., LERNER M., KRISHNAN K. M., BARTLETT N., Synthetic Metals, 34, 1-7, (1989)

[5] MOORE A. W., Proceedings of the 18th Biennal Carbon Conference, Worcester Polytechnic Institute, Worcester MA, American Carbon Society, St. Mary PA, 523-524, (1987)

[6] MOORE A. W., STRONG S. L., DOLL G. L., DRESSELHAUS M. S., SPAIN I. L., BOWERS C. W., ISSI J. P., PIRAUX L., J. Appl. Phys., 65, 12, 5109-5118, (1989)

[7] BESMANN T. M., J. Am. Ceram. Soc., Vol. 73, No. 8, 2498-2501, (1990)

[8] SAUGNAC F., TEYSSANDIER F., MARCHAND A., J. Chim. Phys., 89, 1453-1468, (1992)

[9] BOUCHACOURT M., Thèse de Doctorat d'Etat, Université de Grenoble, (1982)

[10] LOWELL C. E., J. Am. Ceram. Soc., 50, 3, 142-144, (1967)

[11] JONES L. E., FECKO D. A., THROWER P. A., Proceedings of the fifth International Carbon Conference, Essen, $22-26$ June, 917-919. (1992)

[12] CROSSLAND C. E., JONES L. E., Proceedings of the fifth International Carbon Conference, Essen, 22-26 June, 863-865, (1992)

[13] DERRE A., FILIPOZZI L., BOUYER F., MARCHAND A., to be published in Journal of Material Science

[14] ADACHI S., FUKUDA S., MOHRI M., YAMASHINA T., J. Nuclear Mat., Vol. 133\&134, 263-267, (1985)

[15] JONES L. E., THROWER P. A., Journal de Chimie Physique, Vol. 84, N. 11/12, 1431-1438, (1987)

[16] WAY B. M., DAHN J. R., TIEDJE T., MYRTLE K., KASRAI M., Physical Review B, Vol. 46, N. 3, 1697-1702, (1992)

[17] PEASE R. S., Acta Crystallog., Vol. 5, 356, (1952) 


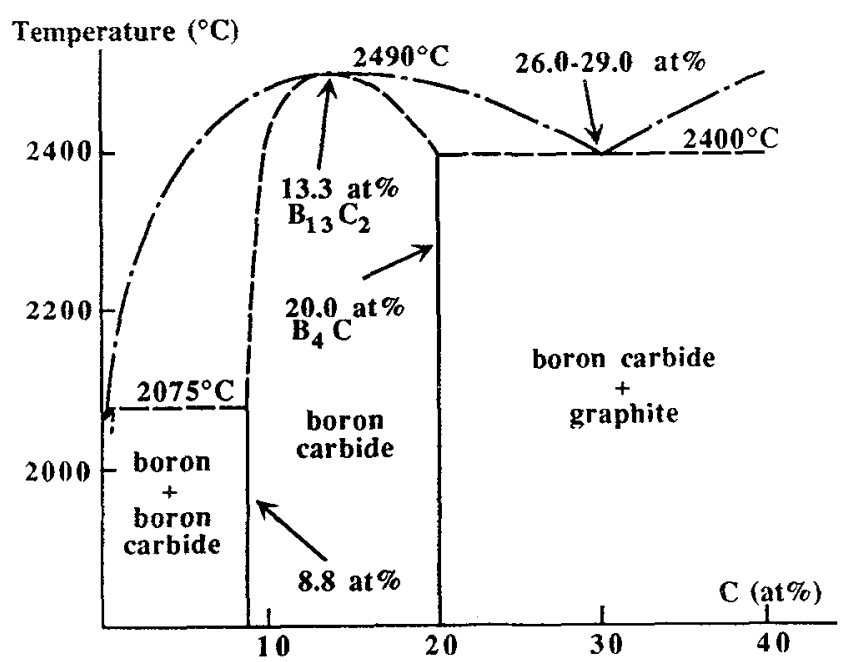

Figure 1: boron rich part of the boron-carbon phase diagram [9]

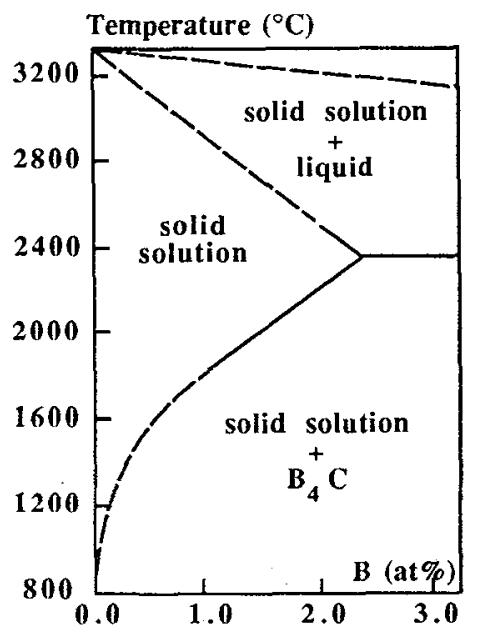

Figure 2: carbon rich part of the carbon-boron phase diagram [10]

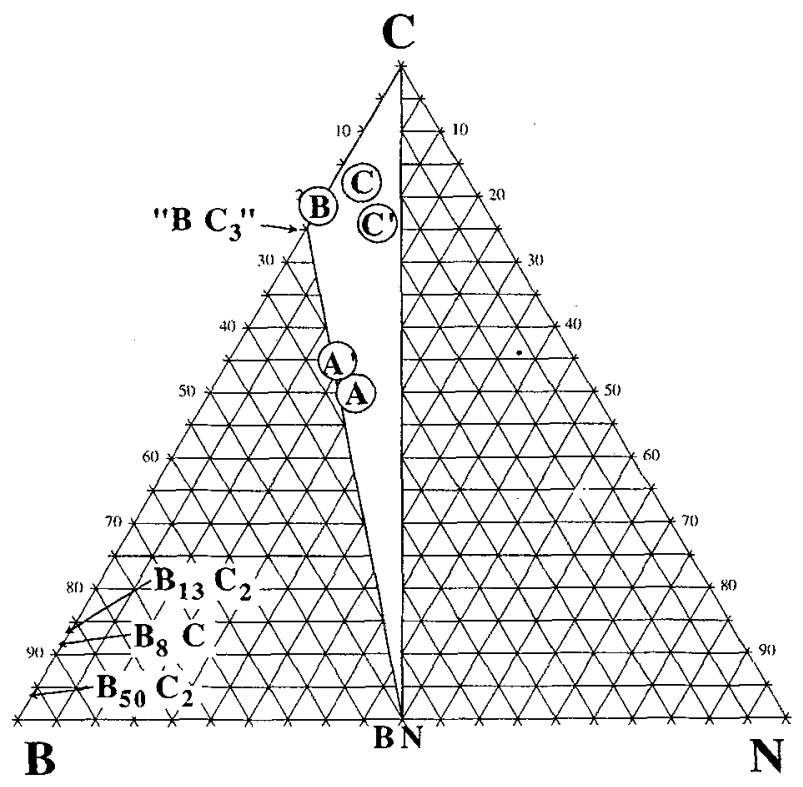

Figure 3: carbon-boron-nitrogen composition diagram showing the $A, A^{\prime}, B, B^{\prime}, C$ and $C^{\prime}$ samples and compositions used 


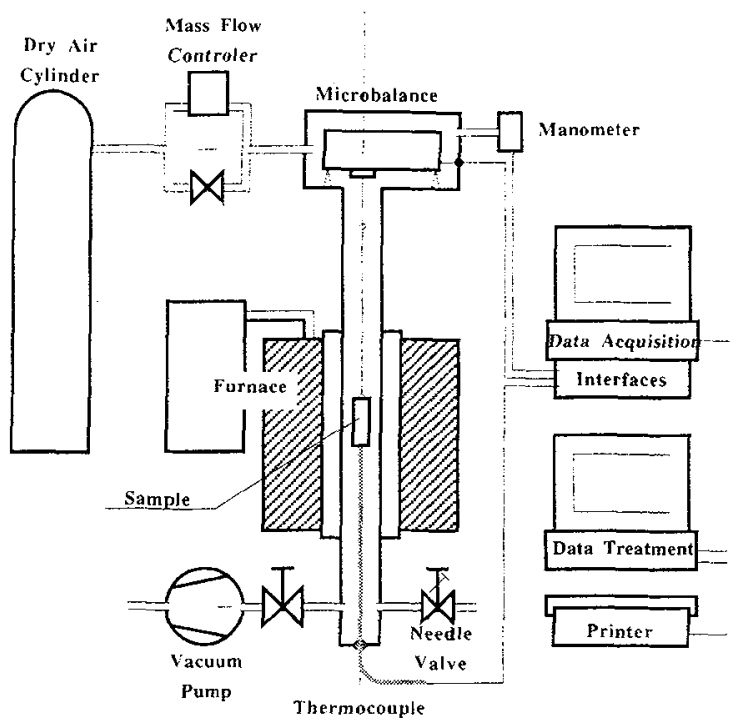

Figure 4: shematic diagram of the apparatus used for the oxidation resistance experiments

Table 1: variation of the surface composition for samples $A^{\prime}, B^{\prime}$ and $C^{\prime}$ versus the highest treatment temperature HTT

\begin{tabular}{|c|c|c|c|c|c|c|c|c|c|}
\hline \multirow{2}{*}{$\begin{array}{c}\text { HTT } \\
\left({ }^{\circ} \mathrm{C}\right)\end{array}$} & \multicolumn{3}{|c|}{ sample A' } & \multicolumn{3}{c|}{ sample B' } & \multicolumn{3}{c|}{ sample C' } \\
\cline { 2 - 11 } & $\mathrm{C}$ at\% & $\mathrm{B}$ at\% & $\mathrm{N}$ at\% & $\mathrm{C}$ at\% & $\mathrm{B}$ at\% & $\mathrm{N}$ at\% & C at\% & B at\% & $\mathrm{N}$ at\% \\
\hline as deposited & 55.2 & 29.0 & 15.8 & 79.1 & 20.9 & - & 76.1 & 15.2 & 8.7 \\
\hline 1500 & 59.0 & 26.3 & 14.7 & 83.0 & 17.0 & - & 80.7 & 15.1 & 4.2 \\
\hline 1750 & 58.2 & 27.2 & 14.6 & 87.0 & 13.0 & - & 82.0 & 12.7 & 5.3 \\
\hline 2000 & 69.6 & 21.2 & 9.2 & 99.0 & 1.0 & - & 83.7 & 10.3 & 6.0 \\
\hline 2250 & 71.0 & 16.9 & 12.1 & 99.1 & 0.9 & & 86.6 & 7.0 & 6.4 \\
\hline 2500 & 99.6 & 0.4 & 0.0 & 98.7 & 1.3 & & 95.4 & 4.5 & 0.0 \\
\hline
\end{tabular}

Table 2: experimental and calculated values of the mass loss of samples $A^{\prime}, B^{\prime}$ and $C^{\prime}$ versus the highest treatment temperature HTT

\begin{tabular}{|c|c|c|c|c|c|c|}
\hline \multirow{2}{*}{$\begin{array}{c}\text { HTT } \\
\left({ }^{\circ} \mathrm{C}\right)\end{array}$} & \multicolumn{2}{|c|}{ sample $\mathrm{A}^{\prime}$} & \multicolumn{2}{c|}{ sample $\mathrm{B}^{\prime}$} & \multicolumn{2}{c|}{ sample $\mathrm{C}^{\prime}$} \\
\cline { 2 - 7 } & $\Delta \mathrm{m} \exp (\%)$ & $\Delta \mathrm{m}$ calc $(\%)$ & $\Delta \mathrm{m} \exp (\%)$ & $\Delta \mathrm{m} \mathrm{calc}(\%)$ & $\Delta \mathrm{m} \exp (\%)$ & $\Delta \mathrm{m} \mathrm{calc}(\%)$ \\
\hline as deposited & - & - & - & - & - & - \\
\hline 1500 & 0.0 & -6.5 & 0.0 & -4.3 & 0.0 & -6.4 \\
\hline 1750 & 0.0 & -5.3 & 0.0 & -8.3 & 0.0 & -7.5 \\
\hline 2000 & 0.0 & -21.1 & 0.0 & -18.5 & 0.0 & -9.0 \\
\hline 2250 & 0.0 & -21.9 & -2.7 & -18.6 & 0.0 & -11.7 \\
\hline 2500 & -24.7 & -44.5 & -17.2 & -18.3 & -18.9 & -22.4 \\
\hline
\end{tabular}




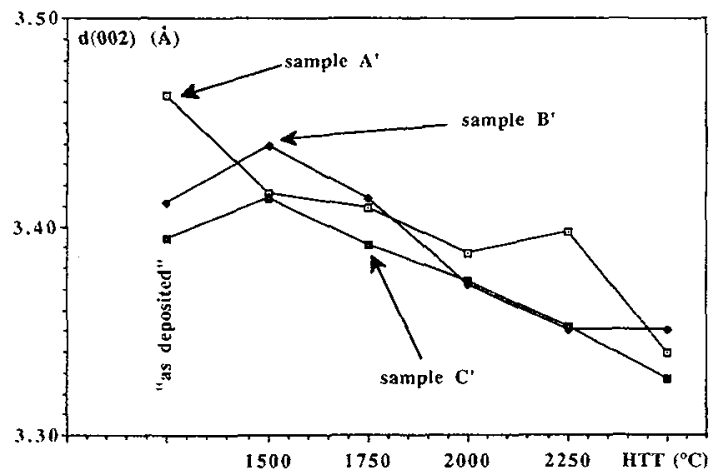

Figure 5: $\mathrm{d}_{002}$ evolution versus the highest treatment temperature HTT for the samples A', $\mathrm{B}^{\prime}$ and $\mathrm{C}^{\prime}$

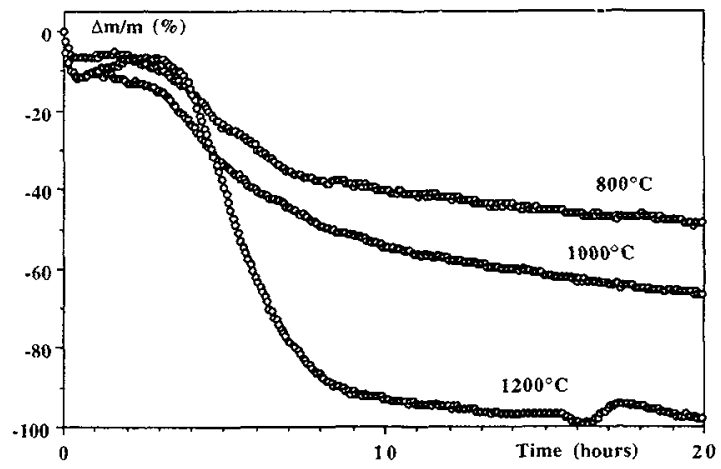

Figure 7: mass loss due to the oxidation of a 24 $\mu \mathrm{m}$ thick coating of sample A versus the time at 800,1000 and $1200^{\circ} \mathrm{C}$

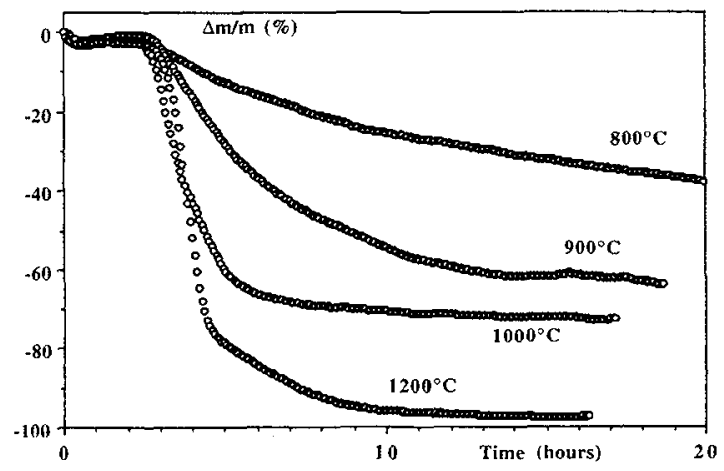

Figure 9: mass loss due to the oxidation of a 80 $\mu \mathrm{m}$ thick coating of sample $\mathrm{C}$ versus the time at $800,900,1000$ and $1200^{\circ} \mathrm{C}$

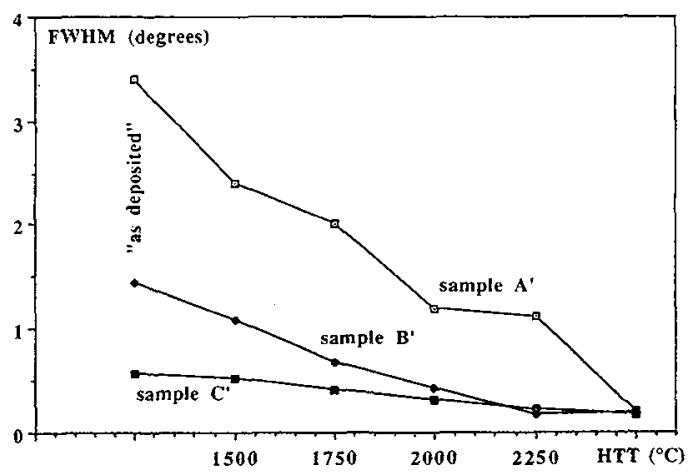

Figure 6: FWHM evolution versus the highest treatment temperature HTT for the samples A', $\mathrm{B}^{\prime}$ and $\mathrm{C}^{\prime}$

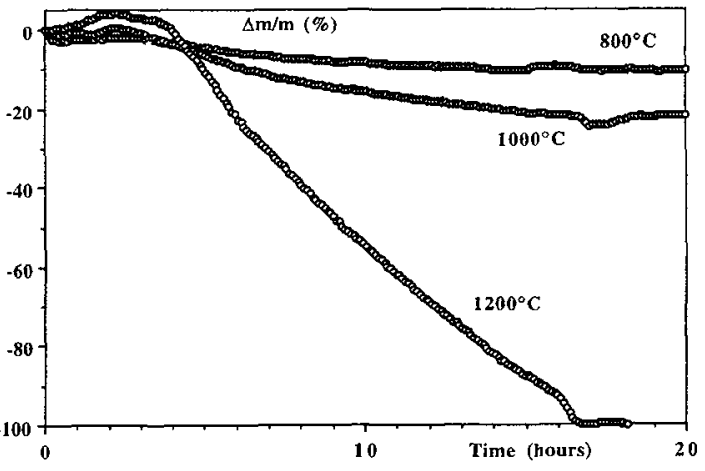

Figure 8: mass loss due to the oxidation of a 93 $\mu \mathrm{m}$ thick coating of sample $\mathrm{B}$ versus the time at 800,1000 and $1200^{\circ} \mathrm{C}$

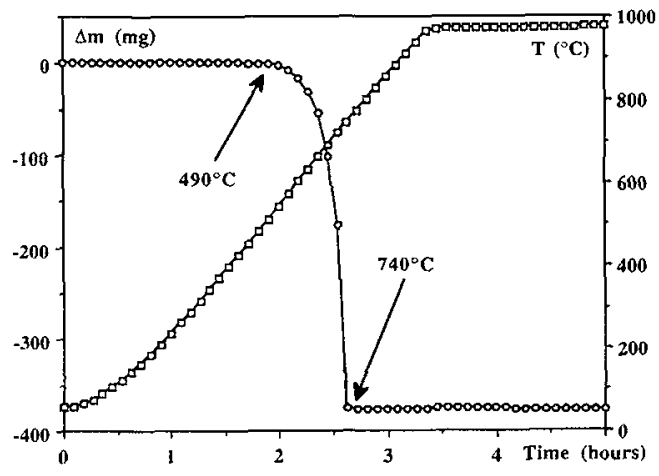

Figure 10: mass loss due to the oxidation of a carbon-carbon composite (initial mass $=367$ $\mathrm{mg}$ ) versus the time 